\title{
Prediction of Mn Contents of Amorphous Co-Mn Thin Films Formed during Electrodeposition
}

\author{
M. Saitou \\ University of the Ryukyus, Department of Mechanical Systems Engineering, 1 Senbaru Nishihara-cho \\ Okinawa, 903-0213, Japan. \\ E-mail: saitou@tec.u-ryukyu.ac.jp
}

doi: $10.20964 / 2020.10 .64$

Received: 10 July 2020 / Accepted: 5 August 2020 / Published: 31 August 2020

The Mn content and crystallographic structure of Co-Mn thin films electrodeposited by rectangular pulse voltages over a megahertz frequency range were investigated using energy dispersive X-ray (EDX) microanalysis and X-ray diffraction (XRD). The EDX analyses demonstrated that in accordance with the phenomenological theory of multi-component electrodeposition (Int. J. Electrochem. Sci., 15 (2020) 6561), the Mn content increased with the cathode potentials, significantly changed at resonant frequencies when the cathode potential was equal to the $\mathrm{Mn}^{2+}$ potential barrier, and approached a saturated value. The potential barriers of $\mathrm{Co}^{2+}$ and $\mathrm{Mn}^{2+}$ were determined to be 1.32 and $2.26 \mathrm{~V}$, respectively. The Co-Mn films containing 40-56 wt $\% \mathrm{Mn}$ were produced from a $\mathrm{Co}^{2+} / \mathrm{Mn}^{2+}$ solution with a mole ratio of 1.2. The XRD analysis revealed that the Co-Mn thin films had amorphous structures.

Keywords: amorphous Co-Mn thin film; cathode potential; potential barrier; electrodeposition

\section{$\underline{\text { FULL TEXT }}$}

(C) 2020 The Authors. Published by ESG (www.electrochemsci.org). This article is an open access article distributed under the terms and conditions of the Creative Commons Attribution license (http://creativecommons.org/licenses/by/4.0/). 